DOI: https://doi.org/10.5007/1980-3532.2016n16p41

\title{
Estatismo e Sistema Interestatal em Mikhail Bakunin
}

\author{
Statism and Interstate System at Mikhail Bakunin
}

\author{
Rafael David Abrunhosa \\ Universidade Federal do Ceará (UFC) \\ Mestrado em Educação \\ absdavidfara@gmail.com
}

\begin{abstract}
Resumo: Bakunin descreveu de modo articulado a interdependência dos principais elementos da modernidade ascendente na Europa do século XIX. A relação entre Estado-Nação, modo de produção capitalista e império são elementos fundamentais em sua obra, bem como o processo de resistência coletiva desenvolvida pelos trabalhadores em defesa da emancipação do trabalho sobre o capital. A perspectiva da totalidade permeia a estrutura desse trabalho posto que no pensamento de Bakunin o desenvolvimento do sistema interestatal se deu de modo intrinsecamente atrelado ao desenvolvimento do modo de produção capitalista. Essa correlação foi estabelecida por meio de uma construção histórica de Bakunin.
\end{abstract}

Palavras-Chave: Bakunin. Estatismo. Totalidade. Império. InterEstatal .

Abstract: Bakunin articulately described the interdependence of the main elements of upward modernity in nineteenth-century Europe. The relation between nation-state, capitalist mode of production and empire are fundamental elements in his work, as well as the process of collective resistance developed by the workers in defense of the emancipation of labor over capital. The perspective of totality permeates the structure of this work, since in Bakunin's thought the development of the interstate system was intrinsically linked to the development of the capitalist mode of production. This correlation was established through a historical construction of Bakunin.

Key-words: Bakunin, Statism, Totality, Empire, Inter-State

Originais recebidos em: 28/12/2017

Aceito para publicação em: 17/07/2018

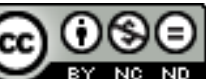

Comercial-Vedada a criação de obras derivadas 3.0 Unported License

Revista Em Debate (UFSC), Florianópolis, volume 16, p. 41-54, 2016. ISSNe 1980-3532 


\section{Introdução}

O lançamento da obra completa de Mikhail Bakunin em CD-ROM pelo Instituto de História-Social de Amsterdã provocou um grande impacto internacional no meio acadêmico. Foram muitos os estudos recentes(LEIR, 2007; MCLAUGHIN, 2002), que de alguma forma recuperam os aspectos filosóficos do pensador russo. A forte citação do nome de Bakunin durante o levante de junho de 2013 demonstra como seu nome está atual, apesar de no Brasil carecer de bibliográfia sobre Bakunin em diversos países sua obra é objeto de estudo de modo mais sistemático. (LEIR, 2007).

Ainda que sua escrita seja demasiada ensaística e poucas vezes sistemática, com exceção de obras como Considerações Filosóficas (1871/2014) e Federalismo, Socialismo e Antiteologismo (1867/1988). Bakunin, contudo, foi um grande pensador/agitador do seu tempo. Ele não apenas participou e apoiou grandes eventos do século XIX como a Primavera dos Povos (1848) e a Comuna de Paris (1871) mas refletiu sobre esses acontecimentos, sobre a Modernidade que emergia de modo violento expondo uma proposta social da burguesia e do conflitos de classes que se agudizava mediante o processo de industrialização e fim do feudalismo.

A estrutura de sua política baseia-se sobretudo na luta de classes que se agudizava de modo distinto na Europa ocidental, já em violento processo de industrialização e migração campo-cidade. A Rússia de Bakunin ainda estava marcada por relações econômicas semi-feudais marcadas pela servidão e o czarismo, enquanto que na Europa ocidental, na qual Bakunin migrou na década de 1840 ocorria inúmeras revoltas burguesas, como na primavera dos povos de 1848 .

Deve-se, portanto, considerar que a política desenvolvida por Bakunin foi marcada por um período histórico de desenvolvimento incipiente do Estado moderno e do sistema capitalista e como esse processo implicou, de modo distinto de seus contemporâneos socialistas europeus, a construção de uma teoria do poder.

Ao conduzirmos nosso estudo ao longo dos anos da obra de Bakunin percebemos a ambição de sua parca obra e encontramos como contraposto muitos comentadores limitados, que não compreenderam a articulação dialética dos postulados do autor. Por isso tentamos apresentar uma leitura de Bakunin quanto a uma análise da relação entre as contradições político-econômica do século XIX, em especial o papel do Estado para o desenvolvimento do capitalismo. 
Bakunin foi um fecundo crítico de sua época, da ebulição do Estado-Nação proveniente de revoluções burguesas e desenvolvimento técnico cientifico a esses processos soube olhar com ceticismo e examinar o que cabia a nova classe que surgia, $o$ proletariado, e que seria refutável.

Bakunin inicia sua vida política na juventude, superando a polêmica entre eslavófilos e ocidentalistas ${ }^{1}$, a qual poderíamos resumir como uma disputa entre concepções de cultura, luta nacional e importação de valores estrangeiros. A posição de Bakunin, que irá dar início à corrente Narodnik na Rússia, é de que a luta nacional não exclui a luta internacional, que valores nacionais podem se agregar a valores produzidos no estrangeiro e que a luta em defesa de princípios políticos locais só pode vencer se unificada a uma perspectiva internacionalista.

As disputas com a social-democracia alemã, no interior da Associação Internacional dos Trabalhadores (MUSTO, 2014), remetiam a muitas das questões que explicitaram a teoria socialista de Bakunin, como a questão se a AIT se deveria apoiar e disputar a construção dos Estado-nações que emergiam na Europa ou se deveriam desenvolver modelos organizativos antiestatistas baseados na tradição, como as organizações de tipo eslava (mir) (FERNANDES, 1982).

De modo geral, o pensamento filosófico de Bakunin guia-se por uma compreensão de modernidade em disputa no qual racionalidade, progresso técnico, desenvolvimento industrial e secularização da politica não deve apenas destruir o poder da tradição, nem negar a capacidade politica dos iletrados e dos saberes ligados a esfera dos costumes. A construção teórica de Bakunin de uma teoria do sistema interestatal, vai de encontro a essa simbiose entre modernidade $\mathrm{x}$ tradição que Bakunin armou como trincheira no século XIX.

É uma trincheira sem romantismo. Bakunin não é um entusiasta da tradição enquanto manutenção dos direitos nobiliárquicos, mas tampouco valida o suposto caráter revolucionário da burguesia, como veremos, entre a burguesia e aristocracia, para Bakunin, há mais uma relação de continuidade do que de ruptura. Essa concepção, na verdade é mais profunda, é até mesmo uma maneira distinta de pensar a modernidade, algo que por espaço não discutiremos aqui. Por isso chamamos atenção ao leitor ao debate sobre o papel civilizador ou não do sistema capitalista no século

\footnotetext{
${ }^{1}$ Para se ter uma compreensão maior da relevância desse debate/embate e suas consequências políticas, ver artigo "O conflito de Modernidades alternativas: Marx/Engels e os Narodniks Russos (ABRUNHOSA, 2014).
}

Revista Em Debate (UFSC), Florianópolis, volume 16, p. 41-54, 2016. ISSNe 1980-3532 
XIX. Esse debate tácito com Marx sobre o papel humanizador ou não do desenvolvimento do Estado e das forças produtivas nos países periféricos se reverte em atualidade em tempos de retorno teórico ao desenvolvimentismo e da manutenção ou não dos impérios na organização sócioprodutiva do sistema capitalista atual.

Estabelecemos uma relação de interdependência antinômica entre duas ideias centrais que a dirigem e que se relaciona a uma concepção mais total de Bakunin sobre a tendência de expansão do sistema interestatal capitalista e a resistência popular dos povos. Bakunin analisou o desenvolvimento da organização politica dos trabalhadores, principalmente apoiado na concepção organizativa do sindicalismo revolucionário em contraposição ao desenvolvimento do sistema interestatal capitalista.

A concepção politica de Bakunin, se desenvolve por sujeitos históricos concretos, por sujeitos e instituições dotadas de interesses e que no embate entre concepções distintas de mundo impõem sua cosmovisão como parte do processo internacional de dominação e expansão de um modelo político-social pré-concebido. Dessa forma, mesmo que existam tendências e leis que possam nortear os rumos da sociedade, a história e a politica sempre é desenvolvida por povos, indivíduos e instituições politicas concretas.

Acreditamos que alguns processos atuais de luta como as do movimento Zapatista e do confederalismo democrático no Curdistão retomam, de modo consciente ou não, o debate sobre autonomia política das luta em relação ao Estado tal como pensara Bakunin. Se essas lutas tenham suas limitações quanto a disputa dos fundos públicos do Estado e o aproveitamento de seus aparelhos creditamos a possível influencia que seus grupos dirigentes (EZLN; PKK) possam ter direta ou indiretamente das ideias de Bakunin.

\section{Estatismo}

O Estado é, segundo Bakunin, a concentração do poder político - monopólio do poder institucional e burocrático (BAKUNIN, 2003; BERTHIER, 2015) - e, portanto, um correlato do capital, enquanto monopólio econômico. O Estado está, para o pensador russo, necessariamente imbricado ao capital, já que a burguesia controla o poder político e econômico. Há, dessa forma, uma determinação recíproca entre as 
esferas econômicas e políticas, entre a concentração política e econômica, o que evidencia a presença, em seu pensamento, de uma dialética entre Estado e capital.

A configuração histórica que Bakunin confere ao Estado moderno nos possibilita demonstrar uma teoria do império elaborada pelo pensador russo. Pois Bakunin não apenas formulou o conceito de Estado em si, ou seja, não parte apenas da concepção de Estado enquanto tal, mas fundamentou, como veremos, sua teoria na disputa entre os Estados no plano geopolítico internacional e em como se orquestrava internacionalmente a concentração política que já existia em escala nacional. Basta observar o longo debate que Bakunin realizou com o Estado prussiano organizado por Bismack e no qual submetemos aqui nesse artigo algumas citações.

A principal obra de Bakunin é o Império Knuto-Germânico e a revolução social organizada apenas em 2014 pela editora Alternativa, até então esse texto havia sido apresentado de forma fragmentada como "Deus e o Estado" por Carlo Cafiero. Nesta obra Bakunin articula a relação teólogica do Estado (por conta de sua influência Feuerbachiana) - ou seja o Estado hegeliano como continuador de Deus - com a formação sócio-histórica do Estado que tem como principio a subjugação e anexação de territórios.

Bakunin, desta forma, historiciza a noção de Estado e, negando sua suposta condição natural dos jurisnaturalistas, afirma que este é fruto das modificações profundas que marcam o início da modernidade. A historicização do Estado e dos fenômenos da política nos serve de guia metodológico na análise das teorias da política do Estado e/ou do Império - ou quaisquer outras - na perspectiva de Bakunin..

Dois fatos históricos, duas revoluções memoráveis haviam constituído o que denominamos mundo moderno, o mundo da civilização burguesa. Uma, conhecida sob o nome Reforma, no começo do século XVI havia destruído a pedra angular do edifício feudal, a onipotência da igreja; ao destruir essa força, ela preparou a ruína do poder independente e quase absoluto dos senhores feudais, que abençoados e protegidos pela igreja, como os reis, e frequentemente mesmo contra os reis, faziam proceder seus direitos diretamente da graça divina; e por isso mesmo ela proporcionou um novo desenvolvimento à emancipação da classe burguesa, lentamente preparada, por sua vez, durante os dois séculos que haviam precedido essa revolução religiosa, pelo desenvolvimento sucessivo das liberdades comunais, e pelo desenvolvimento do comércio e da indústria que haviam sido ao mesmo sua condição e sua consequência necessárias.

Dessa revolução surgiu uma nova potência, não ainda a da burguesia, mas a do Estado, monárquico, constitucional e aristocrático na Inglaterra, monárquico, absoluto, nobiliárquico, militar e burocrático em todo o continente da Europa, com exceção de duas pequenas repúblicas, a Suíça e a Holanda. (BAKUNIN, 2008, p.60) 
Assim, o contexto geopolítico que possibilita a unificação dos grandes Estados nacionais na Europa ocidental é fruto de uma dupla revolução que construiu suas novas bases: 1) A Reforma Protestante, ao questionar e enfraquecer a onipotência das igrejas aliançada com reis e senhores feudais, os arrefeceu e abriu caminho para a racionalização da política e 2) A Revolução Francesa, ao possibilitar que a burguesia assumisse o controle político da sociedade - que, por sua vez, estava intimamente relacionada ao que ficou conhecido como Revolução Industrial, que modificou a estrutura técnica produtiva da sociedade e assim estabeleceu as bases do capitalismo.

O desenvolvimento do modo de produção capitalista, por sua vez, somente foi possível com esse conjunto de revoluções e reformas que deram origem ao Estado moderno. Se do ponto visto histórico podemos afirmar que a unificação dos grandes Estados ocorreu ainda em um período de transição do modo de produção feudal para o capitalista e de forma tal que a centralização política foi condição para a consolidação desse modo de produção universalista, por sua vez os Estados se desenvolveram vertiginosamente com a expansão do modo de produção capitalista, sendo que a consolidação da modernidade baseia-se sobretudo na interdependência e desenvolvimento mútuo dos Estados-nações como forças agentes do desenvolvimento capitalista.

Um novo sistema interestatal emergirá como fruto dessa interdependência e será marcado, segundo Bakunin, pelo desenvolvimento da secularização da política moderna por meio da cientifização/racionalização político burocrático e militar do Estado alemão e sua nova organicidade utilitarista.

O Chanceler Bismarck e o Estado prussiano são os símbolos de uma nova potência imperialista, contemporânea de Bakunin, condensam as principais características dos Estados modernos, esta grande potência representa o uso da ciência na fundamentação teórica politica de um novo tipo e será um espelho para toda a Europa.

Sim, desde o surgimento, na História, a partir da primeira metade do século XVI, de um novo tipo de sistema estatal, a Alemanha, inclusive o Império da Áustria, pelo fato de ser Alemão, nunca, no fundo, deixou de ser, na Europa, o centro de todos os movimentos reacionários (...). Como homem de Estado Inteligente o discípulo de Maquiavel, Senhor Bismarck, incentivava contra todo mundo: contra Deus e contra os Homens, sem excetuar, é evidente, seus correspondentes enciclopedistas, e só acreditava em sua "razão de Estado", apoiando-se como sempre na "força divina dos grandes batalhões", ("Deus está sempre ao lado dos grandes batalhões" gostava de dizer) tanto quanto numa organização econômica 
e numa administração interna a mais perfeita possível, sem dúvida mecânica e despótica. (BAKUNIN, 2014, p163)

O Estado prussiano é símbolo da formulação burocrática politica da modernidade emergente - a ultracentralizarão política, a militarização do Estado, a racionalização da sociedade, o secularismo social e o desenvolvimento da ideia de cultura nacional são, articuladamente, características da nova organização social da hegemonia da classe burguesa.

No processo de disputa dos Estados, sistema interestatal, o Estado prussiano consolidou-se como hegemônico não apenas por desenvolver e centralizar a estrutura político-burocrática-militar, mas também por manter sua hegemonia nesse jogo de disputas internacionais serviu de modelo aos demais Estados nesse novo processo organizativo, exportando uma forma de organização social.

\section{Sistema Interestatal Capitalista}

O desenvolvimento do estatismo surgido no século XVI, determinava uma nova organização política interna, que tem por característica a supressão das ideias divinas/religiosas e a racionalização/secularização da organização interna dos Estados modernos, que são baseados na cientifização e centralização política, administrativa burocrática, militar e econômica. A consequência direta é a conformação de uma nova estrutura política e econômica internacional a que denominamos, baseados em Bakunin, de sistema interestatal capitalista.

A lógica da manutenção do sistema interestatal burguês - que mantém a estrutura político burocrática da sociedade capitalista - é, como bem adverte Bakunin, conquistar para não ser conquistado, ou seja, o sistema necessita, como condição de sobrevivência, da luta ininterrupta pela conquista político territorial.

Essa condição histórica de permanente conflito interestatal, marca da ascensão dos grandes Estados modernos, tem como consequência a concentração progressiva do monopólio do poder político por um restrito grupo que gere as grandes potências.

\footnotetext{
Essa reação nada mais é senão a realização acabada do conceito anti-popular do Estado moderno, o qual tem por único objetivo a organização, na mais vasta escala, da exploração do trabalho, em proveito do capital concentrado em pouquíssimas mãos; o que significa o reinado triunfante da judiaria e dos grandes bancos sob a poderosa proteção das autoridades fiscais, administrativas e policiais, que se apoiam, sobretudo, na força militar, despóticas, por conseguinte, em sua essência, mas que se abrigam, ao mesmo tempo atrás do
} 
jogo parlamentar de um pseudo-regime constitucional. A indústria capitalista e a especulação bancária moderna necessitam, para se desenvolverem-se em toda amplitude desejada, destas grandes centralizações estatais, que sozinhas, são capazes de submeter à sua exploração os milhões e milhões de proletárias da massa popular. (BAKUNIN, 2003, p.35)

A capacidade de organização interna das burocracias, o apoio do monopólio da violência, a expansão territorial, o apoio fiscal do Estado para internacionalização do sistema bancário propiciado por esse novo sistema interestatal utilitarista foram, para Bakunin, o condicionante da expansão do capitalismo monopolista no final do século XIX.

Do ponto de vista histórico, segundo Bakunin, o Estado por meio da concentração politica, da ultra-organização militar e da introdução da administração cientifica nas esferas administrativas possibilitou a consolidação do modo de produção capitalista. Por sua vez, o modo de produção capitalista criou também as condições para a expansão mundial do modelo organizativo constitucionalista burguês.

Bakunin, como observamos, rejeita as teses metafísicas e/ou mecanicistas acerca do Estado, como as que defendem que o mesmo seja determinado unilateralmente pela economia. A compreensão dinâmica e materialista acerca do Estado reside na observação histórica do mesmo, a partir da qual Bakunin demonstra que, sem as novas características citadas, não seria possível nas novas potências a expansão do capital e sua reprodução.

\footnotetext{
O grande capital, por lei que lhe é inerente, é fatalmente levado a invadir tudo. Começou naturalmente explorando os setores do comércio e da indústria que lhe prometeram as maiores vantagens, aqueles cuja exploração era a mais fácil, e acabará, necessariamente, depois de tê-los explorado o suficiente, e pela concorrência que faz a si mesmo nessa exploração, voltando-se em breve para os setores que até aquele momento não havia tocado. Já não se fazem paletós, botas, rendas a máquina? Acreditai, cedo ou tarde, e mais cedo do que tarde, far-se-ão também relógios à maquina. As molas, os escapos, as caixas, a placa metálica, o polimento, o guilhoche, a gravação, se farão máquinas. Os produtos não serão perfeitos quanto aqueles que saem de vossa hábeis mãos, mas custarão muito menos, serão vendidos em muito maior quantidade do que vossos produtos mais perfeitos, que eles acabarão por excluir do mercado. (BAKUNIN, p.104, 2003).
}

As duas características acima comentadas estão amparadas em outras duas tendências - a do desenvolvimento industrial em detrimento da técnica artesanal e a da concentração de capitais, o monopólio. O monopólio precisa dos grandes Estados para se desenvolver, o que determina que potência estatal e monopólio de capitais caminham juntos rumo à centralização econômica e política. 
O desenvolvimento do modo de produção capitalista tem como uma das suas tendências inexoráveis o ingresso no mercado de capitais da produção de caráter doméstico, bem como a incorporação do trabalho assalariado ao que era o antigo trabalho artesanal.

Assim como a indústria capitalista e a especulação bancária - a qual sempre acaba por absorver a primeira, ambas sendo obrigadas, sob a ameaça da falência, a ampliar sem cessar seu campo de atividade em detrimento da pequena especulação e da pequena indústria, condenadas a serem devoradas por elas devem se esforçar para ser únicas e universais, do mesmo modo, o Estado moderno, militar por necessidade, traz em si a irresistível aspiração a tornar-se um Estado universal; (BAKUNIN, 2003, p.36)

A tendência do Estado moderno, tal e qual as indústrias capitalistas, que tendem a se monopolizar, destruindo a concorrência e expandindo sua atuação internacional, é de se tornar universal na disputa dentro do sistema interestatal. As tendências do capital e do sistema político predominante convergem para absorção/destruição da pequena propriedade e dos pequenos Estados nações.

A racionalização das técnicas administrativas burocráticas no processo de centralização e organização política do Estado moderno possibilitou, ao mesmo tempo, a expansão dos Estados-nações, desenvolvendo o processo de quebra de fronteiras nacionais em prol dos impérios e a reprodução ampliada do capital com tendências monopolísticas.

Compreendido que o Estado moderno é essa máquina centralizadora de poderes políticos, administrativos e militares, que serve a uma casta burocrática minoritária da população e que a expansão anexionista externa depende de uma coesão da política administrativa interna, podemos aferir que, para Bakunin, a necessidade da expansão anexionista está fundamentada, dentre outros motivos, na necessidade de garantir cargos burocráticos externos aos aliados internos a fim de garantir a manutenção da máquina política interna na política externa.

O sistema interestatal capitalista tem como característica de seu desenvolvimento: 1) o crescente da miséria/pauperização simultaneamente e 2) a concentração de poder político e de capitais, os monopólios. Podemos aferir então que, para Bakunin, o sistema interestatal capitalista desenvolve a miséria, ou desenvolve o subdesenvolvimento, paralelamente ao desenvolvimento do capital.

No processo de acumulação capitalista, o grande capital desenvolve-se atrelado aos grandes Estados-nações em um único processo combinado de universalização do 
sistema interestatal capitalista. ${ }^{2}$ Bakunin compreende o processo de organização do capital a partir da sua tendência a se monopolizar e a se universalizar a partir de associações/fusões, mas também discorre sobre como esse capital, apesar de internacional, tende a se unificar com o seu Estado nação de origem e representar uma força concentrada ainda maior.

\begin{abstract}
Dissemos e demonstramos, antes, que a sociedade só pode constituir e permanecer um Estado se ela se transforma em Estado conquistador. A mesma concorrência que, no plano econômico, esmaga e devora os pequenos, e até mesmo os médios capitais, estabelecimento industriais, propriedades fundiárias e casas de comércio, esmaga e médios Estados, em proveito dos impérios. Doravante, todo Estado que não se contentar em existir no papel e pela graça de seus vizinhos, pelo tempo que estes quiserem tolerar, mas desejar ser um Estado real, soberano, independente, deve ser necessariamente um Estado conquistador. (BAKUNIN, 2003, p.66) .
\end{abstract}

Para Bakunin, o capitalismo e o Estado moderno, como já observamos, não apenas determinam-se mutuamente, mas também percorrem o mesmo objetivo, pois tanto a indústria capitalista como o Estado moderno disputam cada um em suas esferas a universalização como condição de sobrevivência. De um lado, a acumulação de capital precisa tornar-se mais capital na tendência monopolística e por outro lado, os Estados precisam se expandir como condição de sobrevivência no sistema interestatal moderno.

O sistema interestatal, tal qual foi preconizado por Bakunin, é um sistema baseado na conquista e na busca pelo monopólio do poder político que, se por um lado é determinado pelo modo de produção capitalista, por outro lado também determina esse modo de produção ao sedimentar suas políticas-organizativas. Desse modo, com base na explicação sociológica e integral no sentido da totalidade dialética política-economia, denominamos de sistema interestatal capitalista.

Essa apreensão do desenvolvimento do estatismo e da acumulação de capital em um único movimento integral traz à luz uma nova maneira de encarar o processo de hegemonia da burguesia na sociedade atual. Lança luz em elementos para uma nova perspectiva de superação dessa mesma sociedade e aponta, ainda que de modo primário, a reconstrução de uma teoria do imperialismo total/integral.

\title{
Império
}

\footnotetext{
${ }^{2}$ Apesar de o capitalismo ter passado do século XIX ao XXI por uma série de mutações (e o sistema estatal também) é notório que as grandes corporações capitalistas têm como sede e aliados as grandes potências imperialistas da contemporaneidade.
}

Revista Em Debate (UFSC), Florianópolis, volume 16, p. 41-54, 2016. ISSNe 1980-3532 
O império é uma categoria central na elaboração teórica de Bakunin porque esta surge como principal mecanismo de desenvolvimento da centralização politica militar e econômica da sociedade de classes. Isso significa que o desenvolvimento do sistema interestatal capitalista para Bakunin não é decorrência de supostas leis históricas mecanicistas ou qualquer outra força metafisica que determinaria os rumos da História, mas sujeitos/instituições concretas determinam os rumos da História.

A missão civilizatória do sistema interestatal capitalista, impulsionado pela potência imperialista - o império prussiano na época de Bakunin - é não apenas ingressar no mercado concorrente mundial, pois isso é apenas parte do processo, visto que a tendência geral desse sistema é destruir/desmantelar a autodeterminação dos povos a partir da imposição da lógica da concentração político territorial.

Bakunin, como bem veremos não descarta leis econômicas e politicas como tendências da sociedade moderna, ele até se utiliza desses termos de lei como tendência, mas baseado no materialismo ele percebe que o desenvolvimento desse sistema é conduzido por uma força política concreta, por agentes políticos reais, que no palco sociopolítico implementam uma politica econômica para o mundo em detrimento de outra, o império é exatamente o maior agente de expansão do sistema interestatal capitalista.

Menos de um ano antes da Guerra Franco-prussiana, pelo qual o império de Bismarck se consolidaria como potência europeia, Bakunin fala da necessidade da Prússia subjulgar a França para estabelecer seu conflito regional na Europa, demonstrando as duas características centrais do Estados moderno: 1) a centralização politica e 2) a disputa por hegemonia no conflito interestatal internacional

Porque a imprensa alemã está unânime nesse ponto e tem mil vezes razão: que a Alemanha não pode fazer a cada dois anos sacrifícios inauditos para manter sua independência. É, pois, absolutamente necessário para a nação alemã que pretende ocupar hoje a posição dominante da França na Europa, reduzir a França precisamente ao Estado em que está potência tem mantido até aqui a Itália, fazerlhe tributária, um vice-reinado da Alemanha, do grande Império alemão. (BAKUNIN, 1938, p.70, tradução nossa).

A guerra Franco-Prussiana de 1871 que teve como objetivo a disputa pelos territórios da Alsácia e da Lorena, mas que também provocou a Comuna de Paris, provocou a hegemonia prussiana na Europa, tornando claro algo que Bakunin 
prognosticara tempos antes, manter em toda Europa a subjugação da mesma pela Prussia e todos os demais Estados meros tributários da nação alemã.

A guerra Franco-Prussiana, segundo a teoria politica de império para Bakunin, não foi, mera casualidade. Representa, pois, a disputa incessante por hegemonia no conflito interestatal, a disputa por hegemonia politica estatal na Europa (bélica ou não). Este primado do conflito desmonta as teses republicanas de democracia representativa, de direito internacional, baseadas sobretudo na ideia de paz entre as nações.

$\mathrm{Na}$ teoria de Bakunin a guerra/conflito possui caráter imanente ao sistema estatal, condição de manutenção do império, a inexistência de guerras/conflito significa apenas a manutenção da subjugação internacional e a ultracentralização política.

Dessa forma, o desenvolvimento do sistema interestatal capitalista, para Bakunin, não se dá de forma mecânica e anárquica, mas sim pela ação consciente de sujeitos concretos que atuam em um grande Estado potência e que exportam um modelo politico-social para o resto do mundo.

Como já observamos o sistema interestatal é em-si mesmo conflituoso, contudo esse conflito não é simétrico, mas profundamente assimétrico dado a hegemonia de uma (ou mais) potência Estatal no plano internacional. O império é, grosso modo, a ação assimétrica (de capital, poder político burocrático-militar, conhecimento) de uma (ou mais) potência com as demais.

\footnotetext{
É tão verdadeiro como há hoje, nas grandes capitais, uma tendência ostensiva a se associarem para constituírem capitais monstruosamente formidáveis. A exploração do comércio e da indústria por sociedades anônimas começa a substituir nos países mais industrializados, Inglaterra, Belgica e frança, a exploração dos grandes capitalistas isolados. $\mathrm{E}$, à medida que a civilização e a riqueza nacional dos países mais avançados crescem, a riqueza dos grandes capitalistas aumenta, embora o número dos capitalistas diminua. Uma certa massa de burgueses médios vê-se empurrada para a pequena burguesia, e uma multidão ainda maior de pequenos burgueses se vê inexoravelmente conduzida para o proletariado, para a miséria. (BAKUNIN, 2008, p101)
}

. O império na teoria bakuninista seria, portanto, a força/instrumento potência organizada que: 1) de universalização da acumulação de capital, buscando novos territórios para subsidiar seu crescimento, seja através de matérias-primas/trabalho precarizado ou novos mercados e 2) desenvolveria a tendência anexionista territorialpolítica dos Estados nacionais no sistema interestatal, que precisa expandir-se externamente, criando assim novos cargos burocráticos no exterior para seus aliados, para manter a coesão política interna do seu bloco burocrático administrativo. 
A teoria do império de Bakunin nos apresenta duas tendências complementares a tendência monopolística do capitalismo, dado que a característica da gênese do capitalismo é de que o capital precisa tornar-se mais capital, como vimos na citação, e a tendência anexionista dos Estados modernos, dada a necessidade de expansão/dominação de novos territórios.

Essa análise de Bakunin nos faz refletir sobre o sistema que vivemos desde o final do século XVIII e a encarar o capitalismo não apenas como um modo de produção, mas como um sistema complexo que precisa a todo instante se reproduzir no campo econômico, político e territorial, como condição de sua sobrevivência.

Os Estados Modernos, para Bakunin, necessitam não apenas concentrar progressivamente seu poder político interno a fim de garantir sua supremacia, mas também precisam dominar povos e anexar regiões no plano internacional, a fim de se sustentarem e, por sua vez, não serem subjugado por algum outro Estado com maior poder político/bélico.

O Estado moderno, por sua essência e pelos objetivos que se fixa, é por força um Estado militar, e um Estado militar está condenado, não menos obrigatoriamente, a se tornar um Estado conquistador; se ele próprio não se lançar a conquista, será conquistado, pela simples razão de que por toda parte onde a força existe, é preciso que ela se mostre ou aja. (BAKUNIN, 2003, p36).

A natureza dos Estados modernos, do ponto de vista histórico, é conquistadora/anexionista e o novo sistema interestatal erigido na modernidade impõe uma centralização interna forte e uma política externa agressiva como condição de sobrevivência. Essa tendência anexionista do sistema interestatal demonstra do ponto de vista filosófico a natureza conquistadora das grandes potências estatais.

Essa elaboração teórica nos impele a crer que, na teoria bakuninista, os Estados coexistem no sistema interestatal coagidos/dependentes de grandes potências imperialistas, forçados a aceitar sua lógica dominadora por conta da supremacia bélica e administrativa das potências imperialistas.

O Estado nação potência, o império, seria, portanto, o motor principal do processo de acumulação capitalista a nível internacional e, dessa forma, o imperialismo não seria uma mera fase do sistema capitalista, mas intrínseco ao próprio capital que, desde o seu nascimento, busca se universalizar como único modo de produção e ao Estado, que busca se universalizar como único modo de organização social. 


\section{Referências}

ABRUNHOSA, Rafael. Da Vontade à Liberdade: Ciência, Trabalho e Educação Em Mikhail Bakunin. Monografia-UFC. Fortaleza, 2013.

. O Conflito Entre Projetos De Modernidade De Marx/Engels E Os Narodnik`S Russos. In: Encontro Do Eixo Marxismo, Teoria Crítica E Filosofia Da Educação, 2013, Fortaleza. Anais Do Ii Colóquio Nacional Marx, Marxismo E A PósModernidade, 2013. V. 1. P. 1.

BAKUNIN, Mikhail. A Ciência e a Questão Vital da Revolução. Editora Imaginário. 2009.

- A reação na Alemanha. In: Cadernos Peninsulares, Nova Série, Ensaio 17. Tradução: José Gabriel. Portugal: Editora Assírio \& Alvin, 1976. Pags. 105-127.

De Baixo Para Cima E Da Periferia ao Centro: Textos Politicos, Filosóficos e de Teoria Sociológica de Mikhail Bakunin. Editora Alternativa. 2014.

Estatismo e Anarquia. Editora Imaginário. 2003

. O Catecismo Revolucionario. Editora Imaginário. 2009.

. Socialismo, Federalismo e Anti-teologismo. Editora Cortez. 1988.

O socialismo libertário. São Paulo, Global, 1979.

BERTHIER, René. Bakunin Fazia Politica?. Retirado de <www.arquivobakunin.blogspot.acessado>. Acessado em 22/07/2015.

FERNANDES. Rubem Cesar. Os Dilemas do Socialismo: A controvérsia entre Marx, Engels e os Populistas Russos. Editora Paz e Terra. 1982.

LEIER, Mark. Bakunin the creative passion: a biography. New York: Seven Stories Press, 2009.

MCLAUGHIN, Paul. Mikhail Bakunin: the philosophical basis of anarchism. Algora Publishing, 2002.

MUSTO, Marcelo org. Trabalhadores uni-vos! antologia política da I internacional. São Paulo: Ed. Boitempo. 2014. 